\title{
Cinta Senese burgers with omega-3 fatty acids: effect of storage and type of enrichment on quality characteristics
}

\author{
Aquilani, C. ${ }^{\circledR}$; Pérez-Palacios, T. ${ }^{2}$; Jiménez Martín, E. ${ }^{2}$; Antequera, T. ${ }^{2}$; Bozzi, R. ${ }^{1}$ and Pugliese, C. ${ }^{1}$
}

'Department of Agrifood Production and Environmental Sciences, School of Agriculture, University of Florence, Italy.

${ }^{2}$ Food Technology, School of Veterinary Science-Institute of Meat and Meat Products, University of Extremadura, Cáceres, Spain.

\section{ADDITIONAL KEYWORDS}

Local breeds.

Microencapsulation.

Fish oil.

Lipid oxidation.

\section{SUMMARY}

In Cinta Senese meat, polyunsaturated fatty acids (PUFA) only consists in the 10-11\% of total fat. Moreover, the eicosapentaenoic and docosahexaenoic acids are not present in pork meat, but they are very abundant in fish products. In order to enhance Cinta Senese burgers healthiness, microencapsulated (M) and bulk fish oil (F) were added. The burgers were divided in three groups and underwent three different storage conditions: no storage (TO), chilled storage (T5) and frozen storage (T30). Fattly acid profile and lipid oxidation of enriched burgers were investigated after cooking. $M$ burgers showed significantly higher amount of PUFA at TO and T5, in particular omega-3 PUFA resulted significantly higher in M samples at TO, T5 and T30. TBARs resulted to be influenced by addition, with significantly higher values in $\mathrm{F}$ burgers. In conclusion, fish oil microencapsulation technique appears to be effective to enrich meat in omega-3 fattly acids, protecting added PUFA from oxidation.

\section{Effetto del tipo di conservazione e arricchimento in omega-3 sulla qualità di hamburger di Cinta Senese}

\section{SOMMARIO}

\section{PAROlE CHIAVE AGGIUNTIVE}

Razas locales.

Microencapsulazione.

Olio di pesce.

Ossidazione lipidica.

\section{INFORMATION}

Cronología del artículo.

Recibido/Received: 16.01.2016

Aceptado/Accepted: 05.07.2017

On-line: 15.01 .2018

Correspondencia a los autores/Contact e-mail:

chiara.aquilani@unifi.it

\section{INTRODUCTION}

Among polyunsaturated fatty acids (PUFA) long-chained omega-3 $\alpha$-linolenic acid (ALA C18:3 n-3), eicosapentaenoic acid (EPA C20:5 n-3) and docosahexaenoic acid (DHA C22:6 n-3), were demonstrated to be very beneficial to human health (Bang et al. 1971, p. 1143). So far, many studies have focused on adding these omega-3 PUFA to several food products in order to improve their nutritional characteristics (Valencia et al. 2008, p. 1046; Martìnez et al. 2012, p. 200; Josquin et al. p.81 2012; Keenan et al. 2015, p. 75) and, in a lesser part, to valorize some low demanded products, as Cinta Senese fresh meat. Cinta Senese is a local pig breed reared mainly in Tuscany; although its meat has a PDO label, consumers traditionally used to prefer Cinta Senese cured products as ham and salami. Moreover, Cinta Senese meat, as pork meat in general, is very rich in saturated fatty acids (SFA) being PUFA only the 10-11\% (Pugliese et al. 2005, p. 459) of total fat. Among PUFA, omega-3 ones are poorly represented and generally 
linked to particular feed and management strategies during the fatting period. However, EPA and DHA are never present in meat being characteristic of fish products. Therefore, the aim of this work was to fulfill consumers demand for high quality products and to valorize Cinta Senese fresh meat through the improvement of a largely demanded product: the burger. The enrichment was carried out using fish oil as source of omega-3 EPA and DHA and two different enrichment procedures were tested. Fatty acid profile and lipid oxidation were assessed in order to evaluate the influence of the enrichment procedure on burger quality traits.

\section{MATERIALS AND METHODS}

Multilayered microcapsules were elaborated following the methodology of Jiménez-Martìn et al. (2015, p. 285). Cinta Senese fresh loins were minced and mixed with salt $(2 \%)$, sulfites $(0.05 \%)$ and mashed potato powder $(2.4 \%)$; three experimental groups of burgers were made: control $(\mathrm{C})$ group $(\mathrm{n}=15)$ with no further addition, microcapsules $(M)$ group $(n=15)$ and bulk fish $(F)$ oil group $(n=15)$. Five burgers of each group were immediately examined (T0), 5 of the remaining burgers were stored 5 days at $+4^{\circ} \mathrm{C}$ (T5), while the last were stored during 30 days at $-20{ }^{\circ} \mathrm{C}$ (T30). Physical-chemical and sensory attributes of enriched burgers were investigated after cooking at 165 ${ }^{\circ} \mathrm{C}$ during 6 minutes (American Meat Science Association, 1995).

Fatty acid methyl esters (FAMEs) were prepared by basic transesterification of fat extracted from $5 \mathrm{~g}$ of each burger (Folch et al. 1957, p. 497; A.O.A.C., 2000, reference 963.22) and they were analyzed by gas-chromatography (GC) using a Hewlett-Packard

Table I. Total fat and fatty acids. Different letters in the same raw $(a, b, c)$ indicate significant differences $(\mathrm{P}<0.05)$ over addition within the same storage conditions. Different letters in the same column $(x$, y) indicate significant differences (at least $\mathrm{P}<0.05$ ) over storage (Grasso totale e acidi grassi. Lettere diverse nella stessa riga $(a, b, c)$ indicano differenze significative $(P<0.05)$ per il metodo di addizione a parità di tempo di conservazione. Lettere diverse nella stessa colonna $(x, y)$ indicano differenze significative $($ minimo $\mathrm{P}<0.05)$ per la modalità di conservazione).

\begin{tabular}{|c|c|c|c|c|c|}
\hline & \multirow{2}{*}{ Storage } & \multicolumn{3}{|c|}{ Addition } & \multirow[b]{2}{*}{$\mathbf{P}$} \\
\hline & & C & $\mathbf{M}$ & $\mathbf{F}$ & \\
\hline & T0 & $0.000^{y}$ & $0.072^{a}$ & $0.031^{\text {by }}$ & $<0.001$ \\
\hline \multirow[t]{3}{*}{ EPA } & T5 & 0.009 cy & $0.073^{a}$ & $0.041^{\text {by }}$ & $<0.001$ \\
\hline & T30 & $0.021^{\mathrm{bx}}$ & $0.065^{a}$ & $0.055^{a x}$ & $<0.001$ \\
\hline & T0 & $0.000^{c}$ & 0.099ay & $0.033^{\text {by }}$ & $<0.001$ \\
\hline \multirow[t]{3}{*}{ DHA } & T5 & $0.000^{c}$ & $0.149 \mathrm{ax}$ & $0.047^{\text {by }}$ & $<0.05$ \\
\hline & T30 & $0.000^{\mathrm{b}}$ & $0.095^{a y}$ & $0.0811^{\mathrm{ax}}$ & $<0.001$ \\
\hline & TO & $10.991^{y}$ & $11.465^{y}$ & 11.365 & 0.106 \\
\hline \multirow[t]{3}{*}{ PUFA } & T5 & $11.202^{\mathrm{by}}$ & $11.962^{\mathrm{ax}}$ & $11.415^{\mathrm{ab}}$ & $<0.05$ \\
\hline & T30 & $11.450^{x}$ & $11.645^{x}$ & 11.783 & 0.558 \\
\hline & TO & $0.579 \mathrm{c}$ & $0.781^{a y}$ & 0.674 by & $<0.001$ \\
\hline \multirow[t]{2}{*}{ N3 } & T5 & $0.602^{\mathrm{b}}$ & $0.864^{a x}$ & $0.691^{\text {by }}$ & $<0.001$ \\
\hline & T30 & $0.640^{\mathrm{b}}$ & $0.779 a y$ & $0.765^{\mathrm{ax}^{\mathrm{x}}}$ & $<0.001$ \\
\hline
\end{tabular}

HP-5890A gas chromatograph. Individual FAME peaks were identified by comparison of their retention times with those of standards (Sigma, St. Louis, MO, USA). Peak areas were measured and FAMEs were expressed as area percentage of total area FAMEs (\%).

Lipid oxidation was detected measuring the thiobarbituric acid-reactive substances (TBARS) as described by Salih et al. (1987, p. 1483). Each burger was minced in a kitchen blender, and $2.5 \mathrm{~g}$ were homogenized for $2 \mathrm{~min}$ with $7.5 \mathrm{~mL}$ of $3.86 \%$ perchloric acid and $0.25 \mathrm{~mL}$ of butylatedhydroxytoluene $(4.2 \%)$. This homogenate was filtered and centrifuged (4 min, 3500 $\mathrm{rpm})$ and the supernatant $(2 \mathrm{~mL})$ was mixed with $2 \mathrm{~mL}$ of thiobarbituric acid $0.02 \mathrm{M}$. Parallel to sampling, a standard curve was prepared employing 1,1,3,3- tetraethoxypropane (TEP). The mixture was heated to $90^{\circ} \mathrm{C}$ for $30 \mathrm{~min}$, cooled and centrifuged again ( $2 \mathrm{~min}, 3500$ $\mathrm{rpm})$. Absorbance was measured at $532 \mathrm{~nm}$ on a spectrophotometer (Hitachi U-2000, Tokyo, Japan). TBARS were expressed as $\mathrm{mg} \mathrm{MDA} \mathrm{kg}{ }^{-1}$ sample.

The effect of cooking and type of enrichment were analyzed by ANOVA using IBM SPSS Statistics v.19 and, when significant differences were observed $(\mathrm{P}<0.05)$, they were evaluated by a Tukey's test.

\section{RESULTS AND DISCUSSION}

Table I shows fatty acids (FA) profile of C, M and $\mathrm{F}$ burgers over addition and over storage. The type of addition had significantly influenced the FA profile, especially at T0 and T5, where differences were found between control and modified burgers. Since the amount of PUFAs added was very limited, addition appeared to not affect PUFA group. This is in contrast with the observations of Josquin et al. (2012, p. 83) on modified sausages where the partial replacement of pork back-fat with microcapsules and fish oil had modified the fatty acid profile. At the level of single fatty acids, as expected, EPA and DHA were detected in added samples and among them, the $M$ burgers showed the highest amount $(\mathrm{P}<0.001)$. As a result of it, omega-3 content also resulted to be affected by addition; in fact, modified samples had a greater content $(\mathrm{P}<0.001)$ of omega-3 PUFA than control ones. These results suggest that, during cooking, microencapsulation had protected EPA and DHA from oxidation. Similar observations were reported also by Umesha et al. (2014, p. 654) on enriched biscuits; indeed, after baking, biscuits enriched with encapsulated oil showed a higher content of $\alpha$-linolenic acid than of those with bulk oil.

Frozen storage (T30) resulted to have better preserved EPA, DHA (and consequently omega-3 total content) in F burgers respect of chilled storage. On the contrary in $\mathrm{M}$ burgers, frozen storage had determined a loss of DHA and omega- 3 content if compared to chilled storage. This is probably due to the combination of the longer storage time (30 days) and a number of possible mechanism occurring during the spray-drying process, as well as the larger surface of microencapsulated fish oil in comparison with bulk oil microencapsulation process, which could have promoted omega-3 degradation processes, as suggested by Keenan et al. 


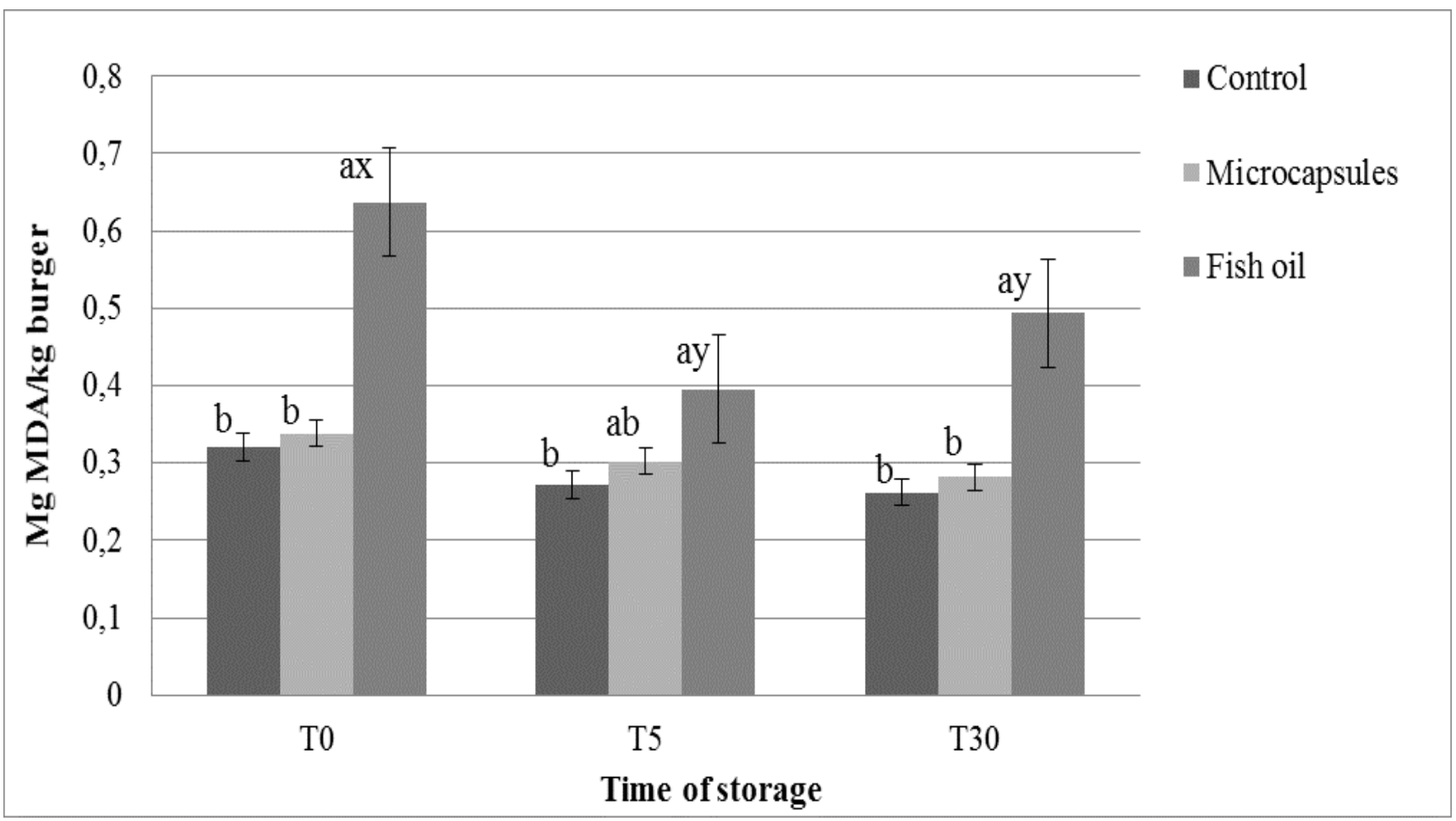

Figure 1. Lipid oxidation over addition and over storage. Different letters $(a, b, c)$ within the same storage condition or among different storage condition $(x, y)$ indicate significant differences (at least $P<0.05)(O s s i d a z i o n e$ lipidica per metodo di addizione e modalità di conservazione. Lettere diverse $(a, b, c)$ all'interno della stessa modalità di conservazione o tra diverse modalità di conservazione $(x, y)$ indicano differenze significative (minimo $\mathrm{P}<0.05)$.

(2015, p. 82). In Figure 1 are reported the TBARS results over addition and over storage. F samples resulted significantly more oxidized than $\mathrm{C}$ and $\mathrm{M}$ samples at $\mathrm{T} 0$ $(\mathrm{P}<0.001)$, T5 $(\mathrm{P}<0.05)$ and T30 $(\mathrm{P}<0.05)$, as reported by Valencia et al. (2008, p. 1050) on fish oil added burgers. At T0 and T30, no significant differences were found between $\mathrm{C}$ and $\mathrm{M}$, while at T5 $\mathrm{M}$ samples showed only slightly higher lipid oxidation values $(\mathrm{P}<0.05)$. Similar results were also observed by Jiménez-Martin et al. (2015, p. 292) in enriched chicken nuggets.

\section{CONCLUSIONS}

In conclusion, fish oil microencapsulation technique appears to be an effective method to enrich meat in omega-3 fatty acids, protecting added PUFA from oxidation during the cooking. Sensory analysis will be carried out to test the consumer's acceptability of these products, taking into account that both the type of addition could have affected the burgers' organoleptic characteristics.

\section{ACKNOWLEDGEMENTS}

This project has received funding from the European Union's Horizon 2020 research and innovation program under grant agreement No 634476 (Project acronym: TREASURE). The content of this paper reflects only the author's view and the European Union Agency is not responsible for any use that may be made of the information it contains. The authors also wish to acknowledge the funding received for this research from both the Junta de Extremadura (Regional Government Board -
Consejería de Economía, Comercio e Innovación) and FEDER by the economic support for research groups: GRU09148 and GRU09025.

\section{BIBLIOGRAPHY}

American Meat Science Association 1995, 'Research guidelines for cookery, sensory evaluation and instrumental tenderness measurements of fresh meat'. Chicago: AMSA.

AOAC, 1990, Association of Official Analytical Chemists, Official Methods of Analysis. 15th Edition.

Bang, HO, Dyerberg, J, \& Nielsen, A 1971, 'Plasma lipid and lipoprotein pattern in greenlandic west-coast Eskimos', The Lancet, vol. 297, no. 7710, pp. 1143-46.

Folch, J, Lees, M, \& Stanley, GH 1957, 'A simple method for the isolation and purification of total lipids from animal tissues', Journal of Biological Chemistry, vol. 226, pp. 497-509.

Jiménez-Martín, E, Pérez-Palacios, T, Carrascal, JR, \& Rojas, TA 2015, 'Enrichment of Chicken Nuggets with Microencapsulated Omega-3 Fish Oil: Effect of Frozen Storage Time on Oxidative Stability and Sensory Quality', Food and Bioprocess Technology, vol. 90, no. 2, pp. 285-97. Josquin, NM, Linssen, JPH, \& Houben, JH 2012, 'Quality characteristics of Dutch-style fermented sausages manufactured with partial replacement of pork back-fat with pure, pre-emulsified or encapsulated fish oil', Meat Science, vol. 90, no. 1, pp. 81-86.

Keenan, DF, Resconi, VC, Smyth, TJ, Botinestean, CK, Lefranc, C, Kerry, JP, \& Hamill, RM 2015. 'The effect of partial-fat substitutions with encapsulated and unencapsulated fish oils on the technological and eating quality of beef burgers over storage', Meat Science, vol. 107, pp. 75-85.

Martínez, B, Miranda, JM, Vázquez, BI, Fente, CA, Franco, CM, Rodríguez, JL, \& Cepeda, A 2012. 'Development of a Hamburger Patty with Healthier Lipid Formulation and Study of its Nutritional, Sensory, and Stability Properties', Food and Bioprocess Technology, vol. 5, no. 1, pp. 200-08. 
Pugliese, C, Bozzi, R, Campodoni, G, Acciaioli, A, Franci, O, \& Gandini, $G$ 2005, 'Performance of Cinta Senese pigs reared outdoors and indoors. 1. Meat and subcutaneous fat characteristics' Meat Science, vol. 69, no. 3, pp. 459-64

Salih, AM, Smith, DM, Price, JF, Dawson, LE 1987, 'Modified extraction 2-Thiobarbituric Acid method for measuring lipid oxidation in poultry' Poultry Science, vol. 66, no. 9, pp. 1483-88.

Umesha, SS, Manohar, RS, Indiramma, AR, Akshitha, S, \& Naidu, KA 2014, 'Enrichment of biscuits with microencapsulated omega-3 fatty acid (Alpha-linolenic acid) rich Garden cress (Lepidium sativum) seed oil: Physical, sensory and storage quality characteristics of biscuits', LWT - Food Science and Technology, vol. 62, no. 1, pp. 654-61.

Valencia, I, O'Grady, MN, Ansorena, D, Astiasarán, I, \& Kerry, JP 2008, 'Enhancement of the nutritional status and quality of fresh pork sausages following the addition of linseed oil, fish oil and natural antioxidants' Meat Science, vol. 80, no. 4, pp. 1046-54. 